\title{
Thysanoptera caught by emergence trapping from oak trees at Hamilton High Parks, South Lanarkshire, including Hoplothrips semicaecus (Uzel) new to Scotland
}

\author{
D.W. Collins ${ }^{1 *}$, J. Robinson ${ }^{1}$, E.G. Hancock ${ }^{1}$, L.M. Maddison ${ }^{2} \&$ J. Stephens ${ }^{1}$ \\ ${ }^{1}$ The Hunterian (Kelvin Hall), University of Glasgow, Glasgow G3 8AW \\ ${ }^{2}$ South Lanarkshire Council, 18 Forrest Street, Blantyre G72 0JP \\ E-mail: entodom@btinternet.com
}

\begin{abstract}
A survey of the saproxylic invertebrate fauna of the Cadzow oaks parkland, South Lanarkshire, Scotland, part of the Hamilton High Parks Site of Special Scientific Interest, was undertaken between April 2017 and April 2018, with additional prior test trapping having started in August 2016. Several different search methodologies were utilised, including Owen emergence traps, flight interception traps, hollow tree traps, and rot hole traps. Large numbers of a non-target group of insects - thrips (Order Thysanoptera) - were noted in some of the traps from the first batch to be examined and separated out for analysis. A total of 370 individuals from eight species was identified, with $85.1 \%$ of these thrips being collected by three Owen emergence traps, a novel methodology for determining the presence, or abundance, of dispersing Thysanoptera. The majority $(92.4 \%)$ of the thrips represented two fungal-feeding phlaeothripid species, Hoplothrips pedicularius and $H$. semicaecus. This is the first report of H. semicaecus from Scotland.
\end{abstract}

\section{INTRODUCTION}

Hamilton High Parks is a 30.7 hectare site immediately south-east of Hamilton, South Lanarkshire, Scotland, which encompasses an area of semi-natural ash- and elm-dominated (Fraxinus spp. or Ulmus spp.) gorge woodland, and two separate areas of wood pasture containing parkland oaks. It is designated as a Site of Special Scientific Interest (SSSI) not only for these two types of woodland plant communities, but also for the rich saproxylic (depending on dead or decayed wood) beetle assemblage associated with the area of open canopy wood pasture containing 300 or more common oak trees (Quercus robur) that are known collectively as the Cadzow oaks (Fig. 1). The site is one of two Scottish mediaeval deer forests with many of the trees over 400 years old, and as a result the parkland is rich in dead wood content. There are fallen limbs at the base of standing trees and a number of trees exhibit hollowed out trunks.

During the 1950s and early 1960s, the renowned coleopterist Roy Albert Crowson (1914-1999) and his wife Elizabeth Anne ("Betty") Crowson (1928-2006),

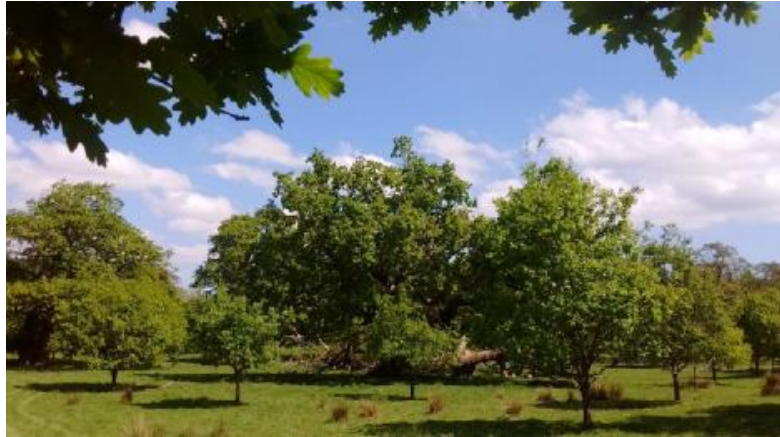

Fig. 1. Hamilton High Parks, South Lanarkshire, Scotland: wood pasture containing parkland oaks (Quercus robur) (Photo: J. Robinson)

also a keen naturalist, collected invertebrates at Hamilton High Parks, predominantly saproxylic Coleoptera. The many rare and interesting species that they uncovered, including a number of 'Nationally Scarce' beetle species, are in part responsible for the site being designated a SSSI. Many of their specimens and notes from Hamilton High Parks, as well as those collected from Clyde Valley and other local woodland sites, were deposited in the Hunterian Museum, University of Glasgow. The Crowsons' findings were published in several journals including The Glasgow Naturalist (e.g. Crowson, 1962, 1964, 1979; Crowson et al., 1966).

These earlier invertebrate surveys inspired a project to return to Hamilton High Parks and undertake a modern investigation, comparing the findings with those from the 1950s and 1960s. Initial test trapping and qualitative sampling began in August 2016. This was followed by a more comprehensive survey of the saproxylic invertebrate fauna of the Cadzow oaks parkland, carried out over 12 months, between April 2017 and April 2018. The primary targets were beetles and spiders, in order to allow comparison with the findings made by the Crowsons, with saproxylic flies also targeted to further enhance knowledge of the site and ultimately help inform site management. Full results of this work will be published in due course. However, during analysis of the catch from the first batch of traps to be examined, 
which included trap catches from both during the initial test trapping phase and the main survey, the presence of large numbers of a non-target group of insects - thrips (Order Thysanoptera) - was noted in some of the traps. These thrips were isolated for separate examination and evaluation, and the results are presented here, including the occurrence of a species not previously recorded from Scotland.

\section{METHODS}

The primary, year-long, survey commenced on 14th April 2017. Sampling utilised a number of trapping methodologies including: 20 flight interception traps (ten hanging in the oak canopy and ten attached to the oak trunks); ten water traps (situated inside the hollow oak trunks); ten rot hole emergence traps; and ten Owen emergence traps filled with wood in varying states of decay, including wind fallen branches with relatively fresh growth, rotten tree sections with and without bark, and sections of loose bark (Fig. 2).

Once set up, traps were left in situ for a full calendar year. In addition, prior to the main survey, the sampling protocol had been tested with one of each type of trap set up on 25th August 2016. In all cases, traps were checked at approximately two or three weekly intervals, occasionally at longer intervals, with the catch being removed for storage and analysis. Traps were all custom built, with a solution of $50 \%$ polypropylene glycol and $50 \%$ water placed in the trap collection bottles. There was also some qualitative searching by hand, and funnel extraction of heart rot and under loose bark. Specimens were rinsed with water and transferred to $70 \%$ ethanol for storage prior to sorting to Order level. Processing of the trap catches remains ongoing as resources, including the availability of taxon specialists, allow; trap catches are not being processed in chronological order. All survey work was planned and supervised by JR, EGH, LM and JS; trap construction, installation, monitoring,

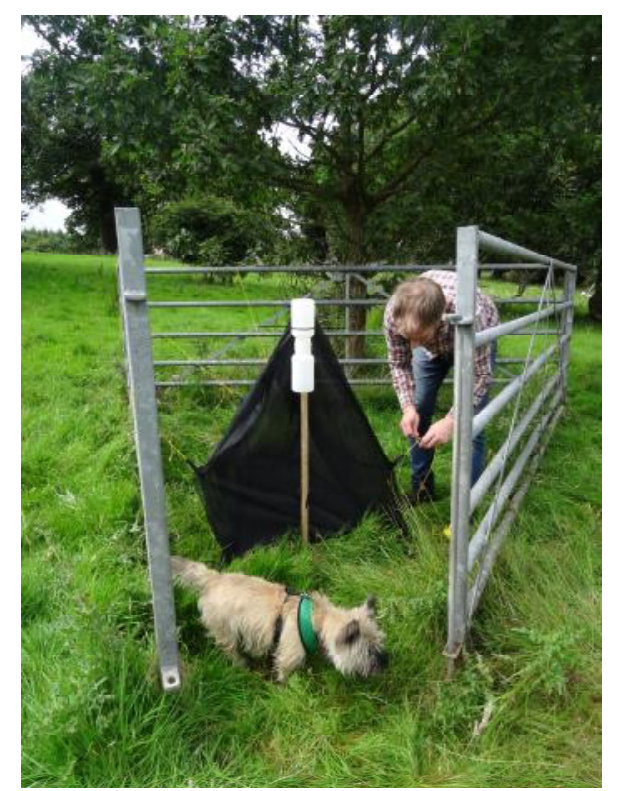

Fig. 2. An Owen emergence trap being set up at Hamilton High Parks. (Photo: J. Robinson) and specimen sorting were supported by numerous invaluable volunteers who are acknowledged below.

Thrips were slide mounted in Canada balsam according to standard methodology (Mound et al., 2018), examined under a GT Vision GXM-L2800 compound microscope at a magnification of up to $\times 400$, and identified using both the key in Mound et al. (1976) and a trial version of the subsequently published online key to British and Irish Thysanoptera (Mound et al., 2018). Confirmation of specific identity was made by comparison with material in the Thysanoptera collection of the Natural History Museum, London (NHM). All slide preparation, identification and evaluation of the thrips found was carried out by DWC.

Voucher specimens have been deposited in the collections at The Hunterian Museum and in the private collection of DWC.

\section{RESULTS}

A total of 370 individual adult thrips was identified from this first batch of trap catches, representing eight species: Aptinothrips rufus Haliday, Limothrips cerealium Haliday, L. denticornis Haliday, Oxythrips bicolor (Reuter), Thrips fuscipennis Haliday (all Thripidae), Hoplothrips fungi (Zetterstedt), $H$. pedicularius (Haliday) and H. semicaecus (Uzel) (all Phlaeothripidae). Thrips were taken from 17 different trap catches, comprising 12 catches from seven separate Owen emergence traps, two from a single aerial flight trap, two from a single rot hole trap, and one from a hollow tree trap. Their occurrence was highly aggregated with 315 individuals $(85.1 \%)$ taken from just four trap catches, from three Owen emergence traps. Furthermore, two species - Hoplothrips pedicularius and H. semicaecus (Fig. 3) - accounted for $92.4 \%$ of all the individuals collected. The results are presented in Table 1.

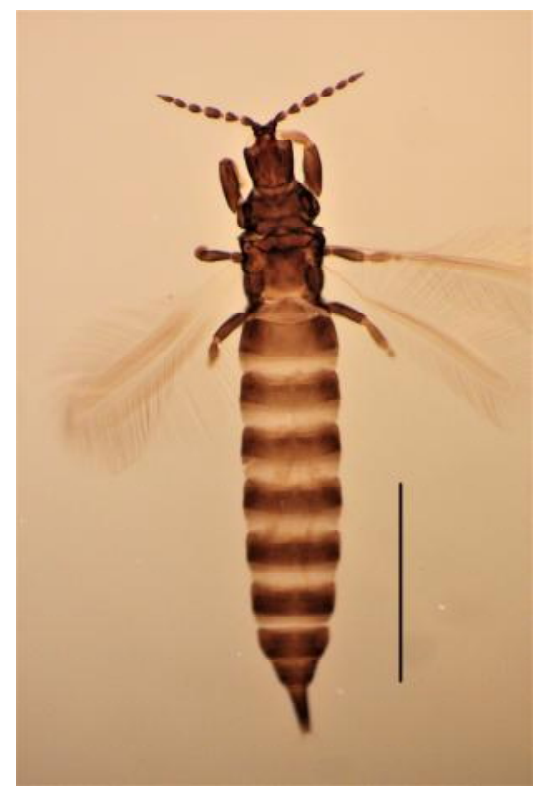

Fig. 3. Hoplothrips semicaecus. An adult macropterous female (slide-mounted, body distended). Scalebar $=1 \mathrm{~mm}$. (Photo: D.W. Collins) 


\begin{tabular}{|c|c|c|c|c|c|c|c|c|c|}
\hline \multirow[b]{2}{*}{ Sample Date } & \multirow[b]{2}{*}{ Trap description/reference } & \multicolumn{5}{|c|}{ Thripidae } & \multicolumn{3}{|c|}{ Phlaeothripidae } \\
\hline & & 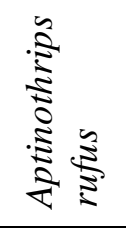 & 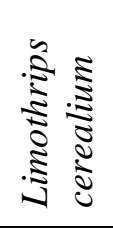 & 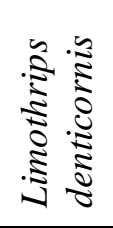 & 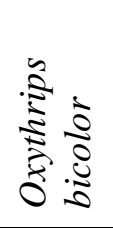 & 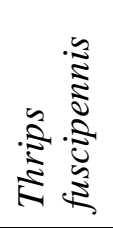 & 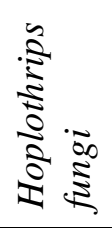 & 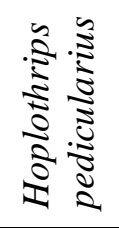 & 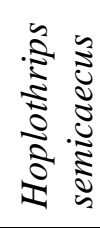 \\
\hline $25.8 .16-8.9 .16$ & Owen emergence trap 4 & $1^{\mathrm{a}}$ & 1 & - & - & 2 & - & - & - \\
\hline $5-22.9 .16$ & Owen emergence trap 4 & - & - & - & - & - & 1 & - & 130 \\
\hline $5-22.9 .16$ & Rot hole trap 50 & - & - & - & - & - & - & - & 6 \\
\hline $6-23.10 .16$ & Aerial flight trap 1 & - & - & - & - & - & - & - & 1 \\
\hline $6-23.10 .16$ & Owen emergence trap 4 & - & - & - & - & - & - & - & 6 \\
\hline $18.10 .16-1.11 .16$ & Owen emergence trap 4 & - & - & - & - & - & 1 & - & 70 \\
\hline $17.11 .16-1.12 .16$ & Aerial flight trap 1 & - & - & - & - & - & - & - & 1 \\
\hline $17.11 .16-1.12 .16$ & Owen emergence trap 4 & - & - & - & - & - & - & - & 5 \\
\hline $6-28.4 .17$ & Rot hole trap 50 & - & - & - & 1 & - & - & - & - \\
\hline $12-25.5 .17$ & Owen emergence trap 21 & - & - & 11 & - & - & - & - & - \\
\hline $12-25.5 .17$ & Owen emergence trap 22 & - & - & 2 & - & 1 & - & 1 & - \\
\hline $8-29.6 .17$ & Owen emergence trap 23 & - & - & - & - & - & 1 & $53^{\mathrm{b}}$ & - \\
\hline $8-29.6 .17$ & Owen emergence trap 24 & - & - & - & - & - & - & - & 1 \\
\hline $8-29.6 .17$ & Owen emergence trap 28 & - & - & - & - & - & 5 & 3 & - \\
\hline $8-29.6 .17$ & Owen emergence trap 29 & - & - & - & - & - & - & $62^{c}$ & 2 \\
\hline \multirow[t]{2}{*}{$18.12 .17-11.1 .18$} & Hollow tree trap 39 & - & - & - & - & - & 1 & - & - \\
\hline & Total & 1 & 1 & 13 & 1 & 3 & 9 & 119 & 223 \\
\hline
\end{tabular}

Table 1. Thysanoptera caught by emergence, and other forms of, trapping at Hamilton High Parks, South Lanarkshire, Scotland. Each trap number refers to a single trap kept in place at a specific location, either though the autumn of 2016 and winter of 2017 (test traps) or for a full calendar year commencing 14 th April 2017 (main survey). All individuals are macropterous females except as annotated: aapterous species - one adult female; bfigure quoted includes four macropterous males; cfigure quoted includes two macropterous males. 


\section{DISCUSSION}

Hoplothrips is a large genus of about 120 nominal species found around the world, whose members occur on the branches and trunks of dead angiosperm trees. Most are presumed to feed on fungal hyphae, though $H$. pedicularius is often associated with brackets of Stereum fungi. Many of the commonest species in the genus, including all three species found at Hamilton High Parks, exhibit wing polymorphism. Both sexes of $H$. fungi and $H$. pedicularius produce macropterous and micropterous morphs, whilst females of $H$. semicaecus may be either macropterous or apterous (only apterous males are known). Wing reduction in Hoplothrips species and a tendency to gregariousness, which is generally common in mycophagous phlaeothripid species, are probably adaptions that allow maximal exploitation of fungal resource on dead wood once located. The strong sexual dimorphism and associated subsocial behaviour found in $H$. pedicularius has been particularly well studied (Crespi, 1986). The literature on the underlying causes of differential wing morphs in fungal-feeding phlaeothripids, including Hoplothrips species, was surveyed briefly by Kobro \& Rafoss (2006). Whether production of fully-winged morphs indicates a phenotypic reaction to sub-optimal food availability or quality, or whether some other causal trigger is involved, is not clear. At Hamilton High Parks, all the $H$. pedicularius adults that have been identified so far emerged from the dead wood in Owen emergence traps 55 to 76 days after the traps were set up. Likewise, the overwhelming majority of H. semicaecus adults emerged either 11 to 28 days or 54 to 68 days after the traps were set up. However, all the $H$. pedicularius adults emerged in May and June of 2017, whereas nearly all the $H$. semicaecus adults emerged during the autumn of 2016, an apparent phenological distinction. But, in the collections of the NHM there are macropterous adult females of $H$. pedicularius from Scotland, taken in September and December, and macropterous adult females of semicaecus, from England, taken in March, July and August. Three individuals of H. semicaecus emerged in June 2017 during this study. Similarly, whilst Morison (1947-1949) noted that macropterous individuals of $H$. fungi migrate in July, two such individuals were found here in the autumn of 2016.

Both $H$. fungi and $H$. pedicularius are common and widespread in Great Britain including the Scottish mainland. Morison (1947-1949) reported the occurrence of large colonies of both species in northeast Scotland, with those of $H$. pedicularius sometimes numbering thousands of individuals and capable of persisting for years. By contrast, this is the first finding of H. semicaecus from Scotland, and it is clearly well-established at Hamilton High Parks.
It has previously been recorded from the southern half of England as well as from Durham and South Yorkshire (Mound et al., 1976; Collins, 2011), and is widespread across Western and Central Europe. However, it appears to become less common in more northerly latitudes and, for example, appears to be rare in both Norway and Sweden in contrast to $H$. pedicularius and, in Norway at least, $H$. fungi (Kobro \& Rafoss, 2006; Gertsson, 2015). The species is also found in North America, Japan and New Zealand. The number and form of the emergent sense cones on the fourth and fifth antennal segments have been used to help distinguish some of the British species of Holothrips. The macropterous female of $H$. semicaecus is unique within the genus in also possessing numerous small sense cones on the ventral surface of the fourth and fifth antennal segments (Fig. 4). The number of emergent sense cones on antennal segments III and IV is variable; the Cadzow oak specimens all exhibit the combination of three sense cones on segment III and four on segment IV, which matches single specimens collected from South Yorkshire (Collins, 2011) and Buckinghamshire (Collins, unpublished data) in the last decade. By contrast, NHM specimens from the 20th century have two sense cones on each segment. The significance of this is unknown, though specimens with the same combination of sense cones as was found at Hamilton High Parks have been recorded in Japan (Okajima, 2006), whilst the number of sense cones on antennal segment IV of macropterous adult females from New Zealand varies between two and four (Mound \& Walker, 1986).

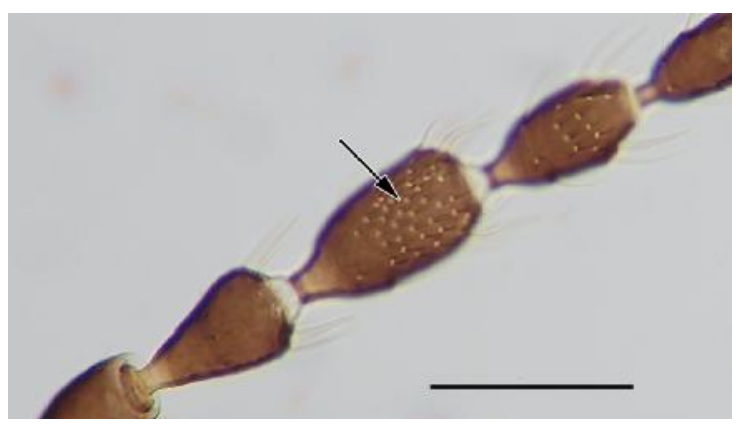

Fig. 4. Hoplothrips semicaecus. Antennal segments III-V, showing the cluster of ventral sense cones on segment IV (arrow). Scalebar $=80 \mu \mathrm{m}$. (Photo: D.W. Collins)

Small numbers of five phytophagous thripid species were also taken, four of which are common and widespread species. All have previously been recorded from "Lanarkshire" (Mound et al., 1976), except $O$. bicolor, a species found on male cones of Scots pine (Pinus sylvestris), which has been widely recorded from north and north-east Scotland. Many terebrantian thrips overwinter in the soil, but some species, including L. cerealium (and probably 
L. denticornis), are known to overwinter as adults under tree bark (see e.g. Lewis, 1962).

Collection records and comparative personal experience suggest that fungal-feeding Phlaeothripidae were more readily collected in Britain up into the middle decades of the last century than they are today (L.A. Mound, pers. comm.). However, the precise reasons for this are unclear, and the effect may be partially the result of sample bias. Thrips are generally taken only from plants within easy reach of the collector, and changes in forestry practice combined with an apparent decrease in insect abundance in recent decades (Leather, 2018) may be contributory factors. Very few studies looking at the insect fauna in tree canopies in Britain have included the Thysanoptera, and as a result there is scant available information concerning those thrips that may be found there. In Britain, a repeat canopy fogging (i.e. insecticide spraying) exercise on common oak trees in Richmond Park, London, between April and October 1984 yielded large numbers of the predatory phlaeothripid species Haplothrips subtilissimus (Haliday) and the phytophagous thripids Drepanothrips reuteri Uzel and Thrips major Uzel (Palmer, 1986). The finding of large numbers of the otherwise rarely collected $D$. reuteri from the tree canopies was illustrative of the limitations of our knowledge of the biology of even the comparatively well characterised British thrips fauna. Among the remaining 19 species collected were small numbers of the fungal-feeding phlaeothripid species Hoplandrothrips ellisi Bagnall, Hoplothrips pedicularius, Hoplothrips ulmi (Fabricius) and Phlaeothrips coriaceus Haliday, as well as six adult specimens of an apparently undescribed species of Hoplothrips (although the specimens do not appear to be extant). A canopy fogging study of three oak trees in the Wyre Forest, Worcestershire, in June and July of 2015 yielded five fungal-feeding phlaoethripid species (Hoplothrips fungi, H. corticis (De Geer), H. pedicularius, H. semicaecus and Phlaeothrips coriaceus) (Skirrow, 2017).

Several studies utilising emergence trapping of adult terebrantian thrips from the soil and leaf litter in orchards have been published (e.g. Parker \& Skinner, 1993; Childers et al., 1994; Gilbert \& Samways, 2018). Other studies have used simple flight interception traps in order to specifically monitor phlaeothripids, whether yellow sticky traps to study the movement of Gynaikothrips uzeli (Zimmerman) adults between weeping fig (Ficus benjamina) plants in a nursery in Mississippi, U.S.A. (Held \& Boyd, 2008) or screen traps in Polish forests to determine the local presence of fungal-feeding species including several Hoplothrips species (Kucharczyk et al., 2015).
Orosz et al. (2016) used Rothamsted-type suction traps to study mass flight of phlaeothripids in Hungary. In Norway, Kobro (2001) deposited fieldcollected Norway spruce (Picea abies) bark in Berlese funnels in order to detect $H$. polysticti (Morison), whilst arboreally-placed photoeclectors have been used to sample bark-living thrips in Slovakia (Duboyský et al., 2010). However, the current authors are not aware of any previous studies using Owen emergence traps to determine the presence, or abundance, of dispersing Thysanoptera. This style of trap is particularly good for targeting species associated with wood and its decay products selectively, as it is a closed unit.

\section{ACKNOWLEDGEMENTS}

This work was funded by the Clyde and Avon Valley Landscape Partnership (CAVLP) and the Glasgow Natural History Society, and supported by Scottish Natural Heritage, who manage the land, and the Hunterian Museum, which provided staff time. Special thanks to South Lanarkshire Council Countryside and Greenspace service for their support and assistance, especially Kerry Thomson, Jo Birkin and Abi Boyd, and to the volunteer army (Bethia Pearson, Hamish Hepburn, Sebastian Dixon, Chris Young, Romane Allanson, Louie Young, D'reen Robinson, Jayne Turkington, William Walton, Wendy Bryan, Diane Hamilton and Kayleigh O'Neil) for assistance with trap construction, installation, maintenance and monitoring, and sample sorting. Paul Brown is thanked for allowing DWC access to the collections of the NHM.

\section{REFERENCES}

Childers, C.C., Nakahara, S. \& Beshear, R.J. (1994). Relative abundance of Frankliniella bispinosa and other species of Thysanoptera emerging from soil beneath 'Navel' orange trees in Florida during Spring flowering. Journal of Entomological Science 29(3), 318-329. https://doi.org/10.18474/0749-8004-29.3.318

Collins, D.W. (2011). The Thysanoptera of Thorne and Hatfield Moors. Thorne and Hatfield Moors Papers 8, 79-85.

Crespi, B.J. (1986). Territoriality and fighting in a colonial thrips, Hoplothrips pedicularius, and sexual dimorphism in Thysanoptera. Ecological Entomology 11, 119-130. https://doi.org/10.1111/j.1365-2311.1986.tb002 86.x

Crowson, R.A. (1962). Observations on Coleoptera in Scottish oak woods. The Glasgow Naturalist 18(4), 177-195.

Crowson, R.A. (1964). Additional records of Coleoptera from Scottish oak-wood sites. The Glasgow Naturalist 18(7), 371-375. 
Crowson, R.A. (1979). Records of Coleoptera from some Clyde Valley sites in Scotland. The Glasgow Naturalist 19(6), 481-484.

Crowson, R.A., Crowson, E.A. \& Brock, J. (1966). Some records of insects and spiders from a locality in central Ayrshire. Entomologist's Monthly Magazine 102, 70-72.

Duboyský, M., Fepor, P., Kucharczyk, H., Masarovič, R. \& Balkovič, J. (2010). Zgrupowania wciornastków (Thysanoptera) pni drzew w różnowiekowych lasach dębowych Słowacji. [Assemblages of bark-dwelling thrips (Thysanoptera) of uneven-aged oak forests in Slovakia]. Sylwan 154, 659-668.

Gertsson, C.A. (2015). An annotated checklist of Thysanoptera (thrips) from the Nordic countries. Entomologisk Tidskrift 136, 185-198.

Gilbert, M.J. \& Samways, M.J. (2018). Mature larval dispersal and adult emergence of the economically significant pest, Scirtothrips aurantii Faure (Thysanoptera: Thripidae), in commercial citrus. Journal of Insect Science 18(2): 32, 1-7.

https://doi.org/10.1093/jisesa/iey028

Held, D.W. \& Boyd, D.W. (2008). Evaluation of sticky traps and insecticides to prevent gall induction by Gynaikothrips uzeli Zimmerman (Thysanoptera: Phlaeothripidae) on Ficus benjamina. Pest Management Science 64, 133140 . https://doi.org/10.1002/ps.1483

Kobro, S. (2001). Hoplothrips polysticti (Thysanoptera) on the wood-rotting polypore Trichaptum abietinum infesting dead Picea abies in Norway. Entomologica Fennica 12, 1521.

https://doi.org/10.33338/ef.84089

Kobro, S. \& Rafoss, T. (2006). Identification of adult males and females of Hoplothrips species (Thysanoptera: Tubulifera) known from Norway, and some deductions on their life history. Entomologica Fennica 17, 184-192. https://doi.org/10.33338/ef.84327

Kucharczyk, H., Kucharczyk, M. \& Wyrozumski, L. (2015). Screen traps as an efficient method in faunal research on fungus-feeding thrips (Tubulifera: Phlaeothripidae). Polish Journal of Entomology 84, 201-210. https://doi.org/10.1515/pjen-2015-0017

Leather, S.R. (2018). "Ecological Armageddon" more evidence for the drastic decline in insect numbers. Annals of Applied Biology 172, 1-3. https://doi.org/10.1111/aab.12410

Lewis, T. (1962). The effects of temperature and relative humidity on mortality in Limothrips cerealium Haliday (Thysanoptera) overwintering in bark. Annals of Applied Biology 50, 313-326. https://doi.org/10.1111/j.1744-7348.1962.tb060 13.x
Morison, G.D. (1947-1949). Thysanoptera of the London area. London Naturalist, Supplement 26, 1-36; 27, 37-75; 28, 76-131.

Mound, L.A., Collins, D.W. \& Hastings, A. (2018). Thysanoptera Britannica et Hibernica - Thrips of the British Isles. Lucidcentral.org, Identic Pty Ltd, Queensland, Australia.

https://keys.lucidcentral.org/keys/v3/british_thr ips/

Accessed 29th October 2019.

Mound, L.A., Morison, G.D., Pitkin, B.R. \& Palmer, J.M. (1976). Thysanoptera. Handbooks for the Identification of British Insects. Vol. I, Part 11. Royal Entomological Society of London.

Mound, L.A. \& Walker, A.K. (1986). Tubulifera (Insecta: Thysanoptera). Fauna of New Zealand 10, 1-140.

Okajima, S. (2006). The Suborder Tubulifera (Thysanoptera). The Insects of Japan 2, 1-720.

Orosz, S., Szénási, A., Puská, J., Ábrahám, R., Fülöp, A. \& Jenser, G. (2016). Observations on the flight pattern of some Phlaeothripidae (Thysanoptera) by using suction trap in Hungary. Acta Universitatis Sapientiae, Agriculture and Environment 8, 16-26. https://doi.org/10.1515/ausae-2016-0002

Palmer, J.M. (1986). Thrips in English oak trees. Entomologist's Gazette 37, 245-252.

Parker, B.L. \& Skinner, M. (1993). Field evaluation of traps for monitoring of emergence of pear thrips (Thysanoptera: Thripidae). Journal of Economic Entomology 86(1), 46-52. https://doi.org/10.1093/jee/86.1.46

Skirrow, M.B. (2017). Fungus-associated thrips (Phlaeothripidae) from Wyre Forest oaks. Worcestershire Record 42, 21-23. 